\title{
The Spectrum of Sexual Abuse in Daycare: An Exploratory Study
}

\author{
Kathleen Coulborn Faller ${ }^{1}$
}

\begin{abstract}
Findings from an exploratory study of 48 children sexually abused in daycare centers and daycare homes are presented. About two thirds were female and one third male. Approximately half of victims were maltreated by a single perpetrator and about half by more than one perpetrator, in the latter instance almost always by both men and women. On average, the children were subjected to 5.3 types of sexual abuse, experienced 2.1 different sorts of threats to obtain their cooperation or prevent disclosure of their victimization, and suffered from 3.7 symptoms regarded as sequelae of sexual abuse. Differences in the characteristics of offenders, victims, the sexual abuse, threats, and sequelae were found based upon the daycare context, that is, whether children were victimized in a center with multiple perpetrators, a center with a single perpetrator, or a daycare home.
\end{abstract}

KEY WORDS: sexual abuse; child sexual abuse; daycare; child care; child maltreatment.

\section{INTRODUCTION}

In recent years, professionals have come to recognize that child sexual abuse is not solely a family problem. Situations of incest in which fathers sexually abuse their daughters represent only a small percentage of cases (Finkelhor, 1987; Russell, 1983), and there is a wide range of extrafamilial contexts in which children are at risk for sexual abuse. One of them is daycare. This article describes an exploratory study of sexual abuse in daycare settings. Its goal is to examine the characteristics of this sexual victimization and its impact on the children. Particular attention will be directed to varia- 
tions in the patterns of sexual abuse in daycare and how these in turn affect victims.

\section{METHOD}

\section{Subjects}

The sample consists of 48 children who were sexually abused in daycare. The victims were referred to the University of Michigan Interdisciplinary Project on Child Abuse and Neglect (IPCAN) between the years 1982 and 1986 by county-based child protective services, state agencies responsible for licensing daycare facilities, law enforcement, the daycare centers themselves, attorneys litigating the cases, and the children's parents. [The most inclusive information on sexual abuse in daycare for the catchment area (the state of Michigan) is found in the records of the Bureau of Regulatory Services (BRS), the state agency in Michigan that licenses daycare facilities and investigates maltreatment in daycare. During the period from 1982 to 1986 , 619 referrals were made for physical and sexual abuse to the BRS. This represents referrals on one percent of daycare facilities. Since the agency does not separate physical and sexual abuse and does not publish descriptive information on substantiated cases, it is not possible to say how representative cases in this study are of reported cases of sexual abuse in daycare.] The primary purposes for seeing these cases were diagnosis and/or treatment. [For an extensive discussion of the diagnostic procedures employed to assure these were valid cases of sexual abuse see Kathleen Coulborn Faller (1988).] However, data were also collected with a view toward furthering an understanding of sexual abuse in daycare.

In all but three cases, the parents as well as the children were interviewed. Only one perpetrator was evaluated. (Intervention with the perpetrator in daycare cases usually focuses on litigation not rehabilitation. In such situations, perpetrators are loath to be interviewed and are usually advised against it by their attorneys. Thus, because of the absence of contact with perpetrators, this study will not further the knowledge of why persons in daycare settings sexually abuse children.) Clinical contact ranged from $11 / 2$ to $20 \mathrm{hrs}$ (mean $=5.3 \mathrm{hr}$ per case). In almost all cases, there was access to extensive records from other agencies. However, the main sources of data for this exploratory study were the children and their parents.

The following information was coded for the 48 cases: (1) type of daycare setting; (2) relationship of the perpetrator to the daycare facility; (3) number of perpetrators per victim; (4) sex of the offender(s) for each victim; (5) victim age at onset of the sexual abuse; (6) victim sex; (7) number and types of sexual abuse; (8) whether the abuse occurred in a dyadic, group, or exploitation situation; (9) the number and types of threats to induce compliance or assure secrecy; and (10) sequelae of the sexual abuse. 
Descriptive statistics and case illustrations will be provided. (Case examples will be taken primarily from cases which have been successfully litigated.) In addition, differences based on the type of daycare setting in which the child was victimized will be presented. Means and distributions were computed for the variables under consideration, and analyses of variance and chi squares were employed to test for statistical significance of differences by daycare setting.

Because the findings are based on clinical cases seen by a particular agency, the reader should be cautioned that while in-depth knowledge of the particular cohort of cases may be gained, the results may not be generalizable to the population of sexual abuse cases in daycare. However, most of the findings are consistent with those of Finkelhor et al. (1987), who conducted a national telephone survey of sexual abuse in daycare with a larger, systematically chosen sample. Nevertheless the findings noted here must be considered preliminary.

\section{RESULTS}

Results will be presented in four sections: findings related to (1) the daycare settings, (2) perpetrator characteristics, (3) victim characteristics, and (4) characteristics of the sexual abuse. Variations in perpetrator, victim, and sexual abuse characteristics by daycare context will be noted.

\section{Daycare Settings}

The children included in this study were sexaully abused in licensed daycare centers and in daycare homes (both licensed and unlicensed). Daycare home is a term used to refer to a facility in the provider's home, which usually serves up to six children. (Age of children in a particular daycare home is usually regulated, as well as the physical premises. Cases referred to IPCAN in which offenders were simply babysitters and not in daycare homes were excluded from this study. They were few in number and often had an additional relationship with the child or family, such as cousin or close family friend.) Thirty-six $(75 \%)$ of the children were sexually abused in daycare centers and $12(25 \%)$ in daycare homes. Half of the daycare home victims were in licensed facilities and half in unlicensed ones.

\section{Characteristics of Perpetrators}

Data were gathered on the number of perpetrators for each victim and each daycare site and the sex of the perpetrator(s) at each site and for each 
victim. Using the type of daycare setting and these findings, a tentative typology for sexual abuse in daycare was developed.

\section{Number of Perpetrators}

The mean of offenders per victim was 2.8. The distribution for number of perpetrators appears in Table I below. The largest proportion of children (close to half) were sexually abused by one person, with about one sixth being abused by four, one seventh by two, and about one tenth by six people.

\section{Sex of Perpetrators}

Cases were differentiated based on whether children were sexually abused by a male, a female, or both male and female. Twenty-three $(47.9 \%)$ of victims were abused by a male, $1(2.1 \%)$ by a female, and $24(50 \%)$ by both males and females.

\section{A Typology for Sexual Abuse in Daycare}

Based upon the above findings, the cases were differentiated into three types. Daycare center cases were divided into those where there were multiple perpetrators $(N=22)$ and those where there was one person involved $(N=14)$. The daycare home cases made up the third type $(N=12)$. These three different types of cases will be referred to as daycare "contexts."

In the multiple perpetrator centers, all of the staff at the center were typically involved in sexual abuse, although not necessarily to an equal extent. By contrast, in single offender centers, the individual sexually abusing children usually operated without the knowledge and support of other staff members. As might.be expected, there are differences in the number of perpetrators by context of abuse. The mean for multiple perpetrator sites was 4.7. [Children occasionally described strangers coming to the center and sexually abusing them or being taken somewhere and being sexually abused. The type of sexual activity (e.g. fondling, oral sex) was coded, and the circumstance

Table I. Distribution for Number of Sexual Abusers per Victim

\begin{tabular}{lcccccccc}
\hline Number of abusers & 1 & 2 & 3 & 4 & 5 & 6 & 7 & 8 \\
\hline Number of cases & 20 & 7 & 3 & 8 & 3 & 5 & 1 & 1 \\
Percentage & 41.7 & 14.6 & 6.3 & 16.7 & 6.3 & 10.4 & 2.1 & 2.1 \\
\hline
\end{tabular}


was coded as sexual exploitation, but the offenders were not counted and included in descriptive information about perpetrators.] The mean number of abusers for single perpetrator situations was 1.1. (In one center included in this group the children said a teacher allowed them to be taken from the center by a man who had a peripheral relationship with the center, and they were then involved in sexual activities and picture-taking with him and another man. It is not clear how much involvement the rest of center staff had in this arrangement, but they were highly resistant to efforts to investigate it. Possibly this situation represents a fourth type of case where there is collusion by the staff but not active participation. However, because this situation is only partially understood, it was included with the single perpetrator cases. Thus, the reason the number is not 1 for number of offenders at single perpetrator sites is because of the two perpetrators at this daycare center. Two of the victims in the study attended that center.) The mean daycare homes was 1.3 ( $F=65.1 ; p<0.0001)$.

In multiple perpetrator settings, there was at least one male employee who was involved as well as one or more females. In the single perpetrator centers, the abusers were all males and were volunteers, custodians, high school or college students working there, or persons providing a peripheral service to the center. In all but three of the daycare home cases, the sexual abuser was not the provider. Offenders were husbands, boyfriends, sons, or friends of the provider. Thus, they were people who had access to the children by virtue of their relationship with the daycare mother.

As might be expected, all of those abused in multiple perpetrator contexts were victimized by both males and females. Children in single perpetrator centers were all abused by males, and of those in daycare homes, nine $(75 \%)$ were victimized by males, one $(8.3 \%$ ) by a female, and two $(16.7 \%)$ by both $\left(\chi^{2}=44 ; p<0.0001\right)$.

The center cases always involved multiple victims, whereas this was the case with only one daycare home.

\section{Characteristics of Victims}

Data were gathered on victim age at the onset of the sexual abuse. These findings will be presented and differences by daycare context will be noted.

\section{Victim Age at Onset}

The mean age of victims at the onset of sexual abuse was 3.9 years, with the youngest child being 1 year and the oldest 9 years. The 1 -year-old victim was in a daycare home and the 9-year-old in an after-school program 
Table II. Victim Age at Onset of Sexual Abuse by Sexual Abuse Context $^{a}$

\begin{tabular}{lccc}
\hline & \multicolumn{2}{c}{ Daycare centers } & \\
\cline { 2 - 3 } & $\begin{array}{c}\text { Multiple } \\
\text { perpetrator }\end{array}$ & $\begin{array}{c}\text { Single } \\
\text { perpetrator }\end{array}$ & Daycare homes \\
\hline Number & 22 & 14 & 12 \\
Mean & 4.1 & 3.0 & 4.6 \\
Stand. dev. & 1.8 & 0.8 & 1.4 \\
\hline${ }^{a}$ F statistic $=4.1 ; p=0.02$. & &
\end{tabular}

at a daycare center. Almost two thirds of the children were either 3 or 4 when the sexual abuse began. Differences by daycare context appear in Table II.

There are differences in age at onset, with the victims in daycare homes being the oldest, followed by those abused by multiple perpetrators, and the youngest being in centers with a single perpetrator. The older age at onset in daycare homes may reflect the older upper age limit of the clientele. The higher mean value for multiple perpetrator centers, when compared to single perpetrator ones, results from the fact that several victims were school-aged children in an after-school program at one multiple offender center.

\section{Victim Sex}

Eighteen $(37.5 \%)$ victims were male and $30(62.5 \%)$ were female. Crosstabulations and analyses of variance were undertaken to look at sex differences on all of the other variables studied. The only statistically significant difference was by context of the sexual abuse. The findings appear in Table III below.

In daycare centers, victims are virtually equally distributed between boys and girls, while more than $90 \%$ of victims in daycare homes are girls. A possible explanation for this finding is that perpetrators in daycare centers are

Table III. Victim Sex by Sexual Abuse Context ${ }^{a}$

\begin{tabular}{|c|c|c|c|c|c|c|}
\hline & \multicolumn{4}{|c|}{ Daycare centers } & \multirow{2}{*}{\multicolumn{2}{|c|}{$\begin{array}{c}\text { Daycare } \\
\text { homes }\end{array}$}} \\
\hline & \multicolumn{2}{|c|}{$\begin{array}{c}\text { Multiple } \\
\text { perpetrator }\end{array}$} & \multicolumn{2}{|c|}{$\begin{array}{c}\text { Single } \\
\text { perpetrator }\end{array}$} & & \\
\hline & $(N)$ & $(\%)$ & $(N)$ & $(\%)$ & $(N)$ & $(\%)$ \\
\hline Male & 10 & 45.5 & 7 & 50.0 & 1 & 8.3 \\
\hline Female & 12 & 54.5 & 7 & 50.0 & 11 & 91.7 \\
\hline
\end{tabular}


different from those in daycare homes. It seems reasonable to conclude that offenders in daycare centers are more likely to have actively sought situations that afford them the opportunity to sexually abuse. If this is so, they are more likely than those abusing in daycare homes to be pedophiles, that is persons whose primary sexual orientation is toward children and who are more likely to victimize boys (Faller, 1988; Groth et al., 1982). In contrast, sexual abusers in daycare homes probably do not prefer children, but, according to Groth's typology, are regressed offenders and therefore more likely to choose female victims (Groth et al., 1982).

\section{Characteristics of the Sexual Abuse}

In this section, information will be presented on the number and kinds of sexual abuse the victims experienced, the circumstances of the sexual encounters, the number and types of threats employed by perpetrators to gain cooperation or assure secrecy, and the sequelae of the sexual abuse. Differences by sexual abuse context will also be noted.

\section{Types of Sexual Abuse}

Children were the primary sources of data about the kinds of sexual abuse they experienced. This information was obtained by asking open-ended questions about their perceptions of the caretaker(s) or the center and by asking what happened at the daycare site or what the caretaker did. Probes were used to elicit additional details. The sexual acts described were categorized; then, the categories were collapsed for purposes of analysis. The collapsed categories are as follows: fondling, oral sex, intercourse, other penetration, and other.

Fondling included elicited and inflicted touching of intimate parts as well as situations where children were required to fondle each other. Close to $50 \%$ of the fondling experiences were inflicted upon the victim, $33.8 \%$ elicited by the perpetrator, and $18.9 \%$ were situations of mutual fondling between children.

Oral sex included fellatio, either inflicted or elicited, cunnilingus (elicited or inflicted), and fellatio with ejaculation into the mouth. Approximately $70 \%$ of oral sex was fellatio, $9.3 \%$ (seven cases) cunnilingus, and about one fifth ejaculation into the victim's mouth.

Intercourse could be either vaginal or anal; anal represented a third and vaginal two thirds of the intercourse cases. 
Table IV. Distribution for Types of Sexual Abuse

\begin{tabular}{lccccc} 
& Fondling & Oral & $\begin{array}{c}\text { Inter- } \\
\text { course }\end{array}$ & $\begin{array}{c}\text { Other } \\
\text { penetration }\end{array}$ & Other \\
\hline Number & 74 & 75 & 51 & 17 & 34 \\
Percentage & 29.4 & 29.8 & 20.2 & 6.8 & 13.5 \\
\hline
\end{tabular}

Other penetration consisted of digital intrusion into the vagina or the anus of the victim, and insertion of objects into the vagina or anus. More than $80 \%$ of the cases were of digital penetration. An example of object insertion was a bottle being forced into the anus of a male victim.

The category, other, included such activities as the perpetrator rubbing his penis on the child's belly, the offender kissing the victim's neck, stomach, or chest, and the victim being required to suck the perpetrator's breasts. In addition, such activities as going to the graveyard and engaging in sexual activities, sex with animals, dressing up in costumes and having sex, and apparently satanic practices involving sex were classified as other.

No attempt was made to collect data on the number of instances of sexual abuse. What was coded was each type of sexual abuse a child reported experiencing with each perpetrator or, in some cases, with another victim. Therefore, fellatio would be coded twice if the child described it with two different persons.

Victims on average experienced 5.3 types of sexual abuse. Although the number is very high, it is no doubt an underestimate because disclosure of sexual abuse is a process that may take days, months, or even years. Also, many of the children were still involved in that process. The distribution for types of sexual abuse reported appears in Table IV above. As the table indicates, the most common types of abuse for these children were fondling and oral sex, each comprising almost $30 \%$ of the intances. About a fifth of the experiences were some form of intercourse.

Differences in number of types of victimization per child for the three daycare contexts were found. Victims at the multiple perpetrator centers suffered a mean of 7.7 types of sexual abuse, those in single perpetrator sites 3.8 , and those in daycare homes $2.7(F=13.4 ; p<0.0001)$.

\section{Circumstances of the Victimization}

Children might experience these types of sexual abuse in three possible situations: dyadic encounters, group sexual activities, and situations where they were involved in sexual exploitation. Dyadic situations involved one victim and one offender. 
Table V. Number of Victims Involved in Group Sex and Exploitation by Sexual Abuse Context ${ }^{2}$

\begin{tabular}{|c|c|c|c|c|c|c|}
\hline & \multicolumn{4}{|c|}{ Daycare centers } & & \\
\hline & \multicolumn{2}{|c|}{$\begin{array}{c}\text { Multiple } \\
\text { perpetrator }\end{array}$} & \multicolumn{2}{|c|}{$\begin{array}{c}\text { Single } \\
\text { perpetrator }\end{array}$} & \multicolumn{2}{|c|}{$\begin{array}{c}\text { Daycare } \\
\text { homes }\end{array}$} \\
\hline & $\overline{(N)}$ & $(\%)$ & $(N)$ & $(\%)$ & $(N)$ & $(\%)$ \\
\hline Group & 21 & 95.5 & 7 & 50 & 2 & 16.7 \\
\hline Exploitation & 16 & 72.7 & 2 & 14.3 & 2 & 16.7 \\
\hline
\end{tabular}

Group sex was defined as a situation in which at least three people were involved. Thus, it included instances where the perpetrator made the children have sex with each other, where a child was required to have sex with more than one adult, sexual games involving several children and sometimes more than one adult, as well as situations with multiple perpetrators and multiple victims. Two thirds of group sex episodes involved children being forced to have sex with each other. An example of a sexual game was described by one boy. He said the male offender played the guitar, and would take the boys into the boys' bathroom, make them take off their clothes, and pretend he was playing the guitar on their penises, "going back and forth along the row of us, wap, wap, wap."

Sexual exploitation included two situations: allowing someone outside the daycare center to use the children as sexual objects, and taking pictures of the children or children and adults in various sexual activities. An example of the former is the description two 4-year-old girls gave of being taken away from the center to a place where they had to perform oral sex on three men they did not know. It is unclear whether the pictures that were taken were sold for profit; however, they were used as a means to coerce compliance and prevent disclosure. Occasionally, pictures of some children were employed to encourage others to become involved in sexual activity. If a child experienced both picture-taking and exploitation, each was coded for this analysis. Sexual exploitation might take place in a dyadic or group circumstance. However, that sexual encounter was coded as exploitation rather than dyadic or group sex. Seventy-five percent of the instances of exploitation consisted of picture-taking.

Forty-one $(85.4 \%)$ of the victims were involved in dyadic sex, $30(62.5 \%)$ in group sex, and $20(41.7 \%)$ in sexual exploitation. There were significant differences in the proportion of children subjected to group sex and sexual exploitation by daycare setting (Table V). Group sex was reported by almost every victim of sexual abuse at the multiple offender sites and half of the 
victims at single offenders sites. In contrast, slightly more than $15 \%$ of victims in daycare homes described such abuse. Further, exploitation was characteristic of sexual abuse at multiple perpetrator sites, having been experienced by almost three-fourths of victims at such locales.

\section{Threats}

Authorities on sexual abuse have observed that the offender often employs threats in the process of sexual abuse (Burgess and Holmstrom, 1978; Jones, 1987; Jones and McQuiston, 1986; Russell, 1986; Sgroi, 1982). Threats can be used for the purpose of eliciting involvement in or maintaining secrecy about sexual abuse. For our cases, only a small number of threats appeared to be solely for the purpose of gaining cooperation. However, a case in point was that of a 6-year-old whose father was in the hospital with leukemia. A male perpetrator threatened to follow the boy's mother to the hospital, find the father, and kill him if the boy did not engage in intercourse with his sister. A number of threats seemed to have dual purposes, to elicit compliance and maintain silence. And many children were subjected to threats to prevent them from disclosing.

Threats to induce compliance, to engender silence, and for both purposes were combined and classified into six types: (1) threats of harm to the child or a significant other; (2) death threats to the victim or a significant other; (3) "scary person" or "scary place" threats; (4) threats implying the child is the wrongdoer; (5) killing or harming animals and indicating the same would happen to the child; and (6) other threats.

A given threat was coded only once even though it might be made repeatedly. However, if the same act was threatened against several people, it was coded as a separate threat for each target person. Thus, if a perpetrator said he would cut both the child's mother and father to pieces with his knife, this was coded as two separate threats.

Harm could be of a variety of types. For example, one offender, who had subjected a 5-year-old girl to intercourse twice, told her he would put his penis in her mouth if she told. As a rule, unless the perpetrator explicitly stated the threatened act was intended to kill, it was coded as harm. For instance, one perpetrator threatened to stab a 4-year-old girl's stepfather with a fork. This was coded as a threat of harm. Similarly, there were a number of threats involving drugs, medicines, poisons, and needles, and sometimes the children described these being administered to them. However, the children survived. Therefore, if there was no explicit statement that the effect would be lethal, it was coded as harm.

Threats with guns and knives were treated somewhat differently. If the perpetrator merely said he or she had a weapon, showed the child the weapon, 
or pointed it at the child, this was coded as harm. If a shooting or stabbing was threatened, it was assumed this would be lethal and it was so coded. For example, one victim described being sexually abused with her two best friends. She said that the offender had a gun which he showed them. He also placed the barrel of the gun in the vagina of her friend, but he did not make any verbal statement. These activities were coded as harm. However, on a subsequent occasion he threatened to shoot the girl and her mother if she told. These were coded as death threats.

Death threats were very compelling for the children and extremely traumatic. Illustrative is the case of the 6-year-old boy mentioned above, who was threatened with his father's death to obtain cooperation. Within a matter of a few days the boy's father did die. The perpetrator then told the child that he had killed his father and that he had done this by shooting the father through the heart. He assured the boy that because of the manner of death, his father would not go to heaven. Further he threatened to shoot the boy, his little sister, and his mother through the heart so that they too would not go to heaven if the boy told about the sexual abuse.

The term, scary person, was used when the perpetrator attributed special powers to himself with the implication that these would allow him to retaliate against the child despite preventative measures. For example, a perpetrator told several children he was stronger than the Incredible Hulk, and therefore any attempts to protect them from him would be of no avail. Scary person was also coded for situations where the perpetrator acted or dressed in a manner intended to frighten the child. For instance, one female perpetrator dressed herself as a witch.

The term, scary place, meant the perpetrator threatened to send or put the victim in a frightening place if he or she told. For instance, one offender took the children into the kitchen and made them each crawl in the oven and then he closed the door for what the children said was a long time. They were told that if they revealed the sexual abuse, they would be cooked in the oven.

Activities coded as threats implying the victim is the wrongdoer include threatening to tell the police that the child has been involved in sexual abuse, threatening the victim with jail, telling children their parents wouldn't love them anymore when they found out, and threatening to show the pictures of the child involved in sexual acts to their parents, the police, the newspaper, or the public. The latter were particularly compelling when pictures had been taken of the children involved in sex with other children, especially younger siblings.

There were just seven animal threats coded. One child who was almost 3 when abused told of how the perpetrator said that he had killed the center's pet rabbit and cooked it into rabbit stew, which he made her eat. She said it was terrible because it had the fur and bones in it. He told the child if 
she revealed the sexual activities at the center, he would make her into stew just like the rabbit.

Events coded as other were fairly mild threats. For example, three perpetrators told their victims not to tell because they (the offenders) would get in trouble or would be fired. Two male perpetrators said they would not love their victims anymore if they told. One told the child she would not be able to come to daycare anymore if she disclosed the abuse. Bribes, of which there were only three, were coded as other. Two 3-year-old girls were taken to the store and bought candy as a prelude to requests for sexual favors.

The mean number of threats per victim was 2.1 . There were $15(31.3 \%)$ cases where the children reported no threats and 2 where 10 threats were reported. One quarter of the children described one threat. The distribution for types of threats appears in Table VI. More than a third of the threats involved death, with approximately a quarter consisting of harm to the victim or a significant other; the third most common threat implicated the victim as the wrongdoer, which comprised about a seventh of the reports.

There were significant differences in the number of threats by daycare context. The mean number of threats per victim was 3.9 in the multiple perpetrator centers, 0.36 for single perpetrator centers, and 0.83 for daycare homes $(F=22.1 ; p<0.0001)$. In fact, multiple offender sites were responsible for $84.1 \%$ of the threats against victims.

Although there is a lack of research on the number and types of threats employed by offenders in other contexts, clinical experience along with clinical reports of others (e.g., Summit and MacFarlane, 1985) strongly suggest that the number and quality of threats found in multiple perpetrator sites differ markedly from findings in other situations of sexual abuse.

\section{Sequelae of Sexual Abuse}

Little is known regarding the impact of sexual abuse in daycare. Yet, this is a timely issue for practitioners and is of overriding concern for parents of victimized children. Since all of the children were evaluated within $2 \frac{1}{2}$ years of the cessation of the abuse, the focus of our study was on the initial effects of sexual abuse, rather than on its impact on subsequent development and adult functioning (see Finkelhor and Browne, 1986; Steele and Alexander, 1981). The measure employed to determine sequelae of sexual abuse was subsequent problems and symptoms. We attempted to focus on identifiable behaviors that might be directly related to sexual abuse, rather than more global difficulties (e.g., low self-esteem, lack of trust). The primary source of information was the children's parents. Sumptoms were coded and 
Table VI. Distribution for Types of Threats

\begin{tabular}{lllcccc}
\hline & Harm & Kill & $\begin{array}{c}\text { Scary } \\
\text { pers/place }\end{array}$ & $\begin{array}{c}\text { Victim } \\
\text { wrong }\end{array}$ & $\begin{array}{c}\text { Harm/kill } \\
\text { animals }\end{array}$ & Other \\
\hline Number & 25 & 38 & 8 & 15 & 7 & 8 \\
Percentage & 24.8 & 37.6 & 7.9 & 14.9 & 6.9 & 7.9 \\
\hline
\end{tabular}

collapsed into seven categories: Sexual Behavior, Sleep Problems, Physical Symptoms, Emotional Problems, Behavior Problems, Phobias, and Other.

The primary sexual behaviors were sexual acting out with peers and excessive masturbation. However, a few children sexually accosted adults and some of the older boys sexually victimized younger children.

Sleep problems included nightmares, inability to sleep, and refusal to sleep except under proscribed circumstances, such as with all the windows locked, with a light on, in street clothes, or on the floor. Most sleep problems could be specifically linked to the sexual abuse or accompanying threats. For example, nightmares were often about the perpetrators. The girl who insisted on sleeping on the floor had been warned by a perpetrator that an evil angel was watching over her bed. If she told about the sexual abuse, the angel would murder her in her bed. She insisted on sleeping on the floor so that the angel wouldn't find her.

Physical symptoms consisted primarily of enuresis, encopresis, eating disorders, stomach aches, and headaches. Bowel problems were characteristic of children who had endured anal intercourse, and stomach and headaches were noted for victims who had not yet revealed much of their sexual abuse.

Emotional problems included mood disorders such as depression and anxiety about the sexual abuse as well as specific difficulties (e.g., excessive crying, suicidal ideation or behavior, clinging, and regressed behavior). One 7-year-old girl, who felt her sexual abuse had created problems for the whole family, attempted to drown herself in the apartment complex swimming pool.

Behavior problems consisted of acting out (e.g., physical aggression, firesetting, stealing), social dysfunction, and school difficulties. About three fourths of the behavior problems were various forms of acting out.

Phobias were wideranging and often could be linked directly to acts or threats made by the offender. Some children had pathological fears of insects. One 5-year-old girl was phobic about snow and eventually she revealed that one day the perpetrator had buried her up to her neck in the snow. Some children had fears about their bodies, for example, washing their genitals or of undressing. One 6-year-old girl was terrified of changing into her ballet costume at her grandmother's because a male perpetrator had watched her when she did this at daycare. A few children were school phobic. Fears 
about certain places, about being alone, or about being away from parents were also included in this category. The fears of being separated from parents were often explained by the children as worries that the threats of harm to the parents would be carried out if the children were absent.

In the other category were symptoms such as blaming the parents for the sexual abuse, rumination about the experiences, and refusal to talk about them.

The mean number of symptoms reported per child was 3.7 (range $=$ 0 to 12 ). Two $(4.2 \%)$ children had no symptoms, $10(20.8 \%)$ had one, and $14(29.2 \%)$ had two. Thus, half of the population was described as having one or two problems as a result of the sexual victimization. The distribution for types of sequelae reported appears in Table VII. The most common problem reported (in nearly $25 \%$ of the cases) was sexual activities. This was followed by emotional problems (approximately $20 \%$ of the symptoms). The remainder of the types, with the exception of other sequelae, each included 10 to $15 \%$ of the reports.

Significant differences were found in the number of sequelae reported by context of sexual abuse. The mean number of symptoms for multiple perpetrator centers was 5.7. The mean number of symptoms for single perpetrator centers was 2.1 . For daycare homes, this value was $1.8(F=11.8 ; p<$ 0.0001 ). The statistical significance lies between multiple offender centers and each of the other two contexts. [The impact of other variables on the number and type of sequelae was explored. No differences in number or type of sequelae were found by sex of the victim. Children experiencing emotional problems $(F=5.8 ; p=0.02)$ and problems classified as other $(F=4.6$; $p=0.04$ ) subsequent to the sexual abuse were on average older. The most important predictors of the number of sequelae were the number of types of maltreatment the child had experienced $(r=0.61 ; p<0.0001)$ and the number of threats employed by the perpetrator $(r=0.64 ; p<0.0001)$.]

\section{DISCUSSION}

Any conclusions drawn from this study must be considered tentative because of the need for further research with expanded and representative samples. This current investigation was a preliminary effort to understand sexual abuse in daycare. Nevertheless, the results do argue for differentiating it from other

Table VII. Distribution of Types of Sequelae of Sexual Abuse

\begin{tabular}{lccccccc}
\hline & Sexual & Sleep & Physical & Emotional & Behavior & Phobias & Other \\
\hline Number & 41 & 23 & 19 & 33 & 26 & 28 & 6 \\
Percentage & 23.3 & 13.1 & 10.8 & 18.8 & 14.8 & 15.9 & 3.4 \\
\hline
\end{tabular}


types of sexual abuse and provide clinical information concerning the experiences of some children victimized in daycare. Findings suggest that there is a spectrum of forms of sexual abuse in daycare.

Most serious on practically all measures employed in this study was the victimization of children by multiple abusers in daycare centers. Boys and girls were equally likely to be victimized. Typically, these cases involved all teachers at the center (both male and female offenders), many different kinds of sexual behavior, and a range of threats. Victims sexually abused in this way experienced numerous problems following the discovery.

Children in centers where one perpetrator sexually abused them were also evenly distributed between boys and girls. The abuse did not involve the collusion of all staff, and all were victimized by men. These children suffered fewer types of sexual abuse than those in multiple perpetrator centers. Their experience was generally characterized by an absence of threats.

Children sexually abused in daycare homes were usually abused by someone other than the daycare provider and usually by a single person. Victims were likely to be girls and were older than children in the other two groups at onset of the victimization. These children experienced the fewest number of forms of sexual abuse, but were somewhat more likely than those at single perpetrator centers to be threatened.

Further research is needed concerning children who have been sexually abused in daycare and other out-of-home settings. Of pressing urgency is the need to understand the long-term effects of such trauma. Another issue is whether there are any characteristics that make some children more vulnerable than others. Further, an area that is virtually unexplored is the characteristics of the persons who sexually abuse in these contexts. How do they become involved and why do they maltreat such young children? How is it that female perpetrators victimize in daycare? These are but a few of the many unanswered questions related to children's experiences of sexual abuse in substitute care that warrant attention in future investigative efforts.

\section{REFERENCES}

Burgess, A., and Holmstrom, L., (1978). Accessory to sex: Pressure, sex, and secrecy. In Burgess, A., Groth, N., Holmstrom, L., and Sgroi, S. (eds.), Sexual Assault of Children and Adolescents, Lexington Books, Lexington, Mass.

Faller, K. C. (1988). Child Sexual Abuse: An Interdisciplinary Manual for Diagnosis, Case Management, and Treatment, Columbia University Press, New York.

Finkelhor, D. (1987). Characteristics of sexual offenders. National Conference on Family Violence Research for Practitioners and Policy Makers, Durham, N.H.

Finkelhor, D., and Browne, A., (1986). Initial and long-term effects: A review of the research. In Finkelhor, D. (ed.), Sourcebook on Child Sexual Abuse, Sage, Beverly Hills.

Finkelhor, D., Burns, N., and Williams, L. (1987). Sexual abuse in daycare. Third National Family Violence Research Conference, Durham, N.H. 
Groth, N., Hobson, W., and Gary, T. (1982). The child molester: clinical observations. In Conte, J. and Shore, D. (eds.), Social Work and Sexual Abuse, Haworth Press, New York.

Jones, D. P. H. (1987). Reliable and fictitious accounts of sexual abuse to children. Interperson. Viol. 2: 131-150.

Jones, D. P. H., and McQuiston, M. (1986). Interviewing the Sexually Abused Child (Second edition), The C. Henry Kempe National Center for the Prevention and Treatment of Child Abuse and Neglect, Denver.

Russell, D. (1983). The incidence and prevalence of intrafamilial and extrafamilial sexual abuse of female children. Child Abuse Negl. 7: 133-146.

Russell, D. (1986). The Secret Trauma: Incest in the Lives of Girls and Women, Basic Books, New York.

Sgroi, S. (1982). Handbook of Clinical Intervention in Child Sexual Abuse, Lexington Books, Lexington, Mass.

Steele, B., and Alexander, H. (1981). Long-term effects of sexual abuse in childhood. In Mrazek, P. B., and Kempe, C. H. (eds.), Sexually Abused Children and their Families, Pergamon Press, London.

Summit, R., and MacFarlane, K. (1985). Sexual abuse in daycare centers. Workshop presented at the Seventh National Conference on Child Abuse and Neglect, Chicago, Ill. 